\title{
Influence of Family Environment on the Prevalence of Illicit Drug Use Among Public Secondary School Students in Nakuru Municipality, Nakuru County, Kenya
}

\author{
Mwangi Charles Mucheru ${ }^{1}$, Paul Katamba, $\mathbf{P h D}^{2}$ \\ ${ }^{1,2}$ Bugema University, School of Graduate Studies, P O Box 2544 Nakuru
}

\begin{abstract}
The purpose of the study was to investigate the factors influencing prevalence of illicit drug abuse among students in public secondary schools in Nakuru Municipality. The study was based on a co-relational descriptive survey research design. The target population for this study was 11,597 students and 23 teacher counsellors in public secondary schools in Nakuru Municipality. Stratified random sampling, simple random sampling and purposive sampling techniques were used to select a sample size of 340 students and four teacher counsellors from form one, form two and form four classes. Data was collected using questionnaires and interview schedule and analyzed using mean, standard deviation, frequency counts, percentages and frequency tables. The study concluded that home environment influenced drug abuse among students. Easy availability of drugs within home and school surroundings also influenced students to abuse drugs. Exposure to media with drug content also influenced students to abuse drugs. The study recommends that the school administration should counsel students so as to eradicate associated factors influencing drug abuse among students. The schools should also work closely with the community around and other stakeholders to sensitize students, teachers, non teaching staff and members of community on the dangers of drug abuse.
\end{abstract}

Keywords: Illicit Drug Abuse, Prevalence, Family Background, Nakuru Municipality, Secondary Schools

\section{Introduction}

A drug is any substance that when absorbed into the body may modify one or more physiological functions (Croen, Woesner, Hermann \& Reichgott, 1997). Illicit drug use, also defined as self-administration of illicit drugs, may impair functional ability resulting in the user's physical, social and emotional self-harm (Croen, et al., 1997). A large number of students across all age groups have been exposed to alcohol, tobacco, khat, glue sniffing, bhang and even hard drugs such as heroin and cocaine (Otieno \& Ofulla, 2009). Chebukaka (2014) found that 1.3 billion people use tobacco and 230 million people aged between 14-18 years use illegal drugs. Also, 22 million people in Europe use marijuana. Currently Africa and Asia account for $70 \%$ of global population using opium and its derivatives (UNODC, 2012). In America, the rate of illicit drug use among high school students has increased with age with a prevalence rate of $19.6 \%$ between the ages of 18-20 years (Kwamanga, et al. 2003; Alcohol Concern, 2000). In Britain, cross-sectional studies have shown that at least $40 \%$ of high school students aged 14-18 years have used illicit drugs at least once in their lifetimes. Also among those aged 16-24 years, 38\% of males and 5\% of females regularly drink alcohol (Alcohol Concern, 2000).

In Nigeria, studies have consistently shown that there is considerable prevalence of drugs and substances abuse, with varying prevalence rates found for both overall and specific drug abuse (Abdulkarim, Mokuolu \& Adeniyi, 2005). Factors influencing students to illicit drug use have been identified, among them parental influence. Children from homes where parents take drugs tend to imitate their parents' behaviour and through modelling start using drugs (Ngesu, Ndiku \& Masese, 2008). According to Abdulkarim et al (2005), students may start using illegal drugs due to easily availability, high handedness, lack of concern and failure to address student grievances can also influence students to illicit drug use (Ngesu et al., 2008; Kingala, 2000). It appears that drug abuse and its effects on secondary school students, whose prevalence is assessed in this study, is a worldwide problem with no exception to Kenyan secondary school students. A study undertaken by the Child Welfare Association (CWA) has revealed that one in every 15 Kenyan students is abusing bhang or hashish (Siringi \& Waihenya, 2001). Prevalence of illicit drug abuse is therefore a major problem among students in secondary schools. Previous studies show that more than a fifth (22.7\%) of secondary school students take alcohol (Otieno \& Ofulla, 2009).

In Kenya, following the introduction of Free Secondary Education (FSE) in 2008, most of the students, with no exception to Nakuru Municipality have been attracted to enroll in the sparsely placed day secondary schools countrywide (Ngesu et al., 2008). Since some day schools are located far away from homes, some students are housed by relatives, friends or even rent houses near their schools (Otieno \& Ofulla, 2009). Generally, living away from school and the general problem of poverty in many Kenyan homesteads may encourage illicit drug abuse among students. As a result of lack of school fees, with availability of and access to drugs around schools, idleness among the youth may encourage high prevalence of illicit drug abuse among students aged 14-24 years old. Students in mixed day secondary schools who are not staying with their family may be at risk of getting into the trap of starting to abuse illicit drugs (Ngesu et al., 2008). The most at risk are the students who rent houses near their preferred day schools. Other students at risk of abusing illicit drugs are those who stay with their peer, friends and elderly siblings in either rural or 


\section{International Journal of Science and Research (IJSR) \\ ISSN (Online): 2319-7064 \\ Index Copernicus Value (2013): 6.14 | Impact Factor (2014): 5.611}

urban school settings (Otieno \& Ofulla, 2009). Such students may fall prey to drug abuse due to idleness and lack of parental guidance against the school regulations that require all students to desist from habit of illicit drug abuse (Ngesu et al., 2008). In Nakuru Municipality, Oteyo and Kariuki (2009) have revealed that there exists a significant association between parental influence and drug abuse among students.

\section{Statement of the Problem}

Drug abuse menace is believed to have affected the youthful population as well as secondary school students (Ngesu, Ndiku and Masese, 2008). Despite the worldwide concern and education about the dangers of drug abuse, the prevalence of drug abuse is alarming in secondary schools (Mutiso et al, 2012). Recent studies show that more than a fifth $(22.7 \%)$ of secondary school students takes alcohol (Otieno \& Ofulla, 2009; Oteyo \& Kariuki, 2009). According to Jerop et al (2013), alcohol abuse poses adverse consequences to the learners. For instance, drug abuse has led to social problems in schools such as arsons, school dropout, poor academic performance, sexual immorality, bullying, teenage stress and destruction of school property. In spite of the measures put in place to control drug abuse in schools, this menace is still rampant especially in public secondary schools. The study investigated the influence of family environment on the prevalence of illicit drug use among students in public secondary school in Nakuru Municipality, Nakuru County, Kenya.

\section{Objective of the Study}

To find out the influence of family environment on the level of prevalence of illicit drug abuse among students in public secondary schools in Nakuru Municipality

\section{Literature Review}

\section{Parental role/Family Environment}

Drug abuse is known to have serious consequences at home, schools and in the communities (Elizabeth, Susan \& Suman, 2003). According to Mbalu (2012) children's earliest interactions occur within the family. For this reason, risk factors for taking illicit drugs that affect early development in the family are probably the most crucial. One explanation as to why individuals first become involved with drugs and then escalate to abuse is a biological cause, like having a family history of illicit drug abuse (Mbalu, 2012). According to Kingendo (2010) social-economic set-up children influence their habits. Mbalu (2012) notes that children are more likely to start abusing drugs in a family if there are lack of mutual attachment and nurturing by parents or caregivers. The abuse of drugs and other substances by parents and other caregivers can impede bonding to the family and threaten feelings of security that children need for healthy development (Mbalu, 2012). On the other hand, families can serve a protective function when there is a strong bond between children and their families, parental involvement in a child's life, supportive parenting that meets financial, emotional, cognitive, and social needs and clear limits and consistent enforcement of discipline (Mbalu, 2012).

\section{Methodology}

The study was conducted through co-relational descriptive survey design in which data was collected by interviewing and administering questionnaires to sampled respondents with an aim of studying their attitudes, opinion and habits. The target population for this study was 11,597 students and teacher counselors from 23 public secondary schools in Nakuru Municipality. Quantitative data from the questionnaires were analyzed using frequency counts and frequency tables derived from the responses to the research questions and hypotheses. Qualitative data from interviews was also analyzed descriptively and information presented in the narrative form.

\section{Results and Discussion}

\section{Influence of Family Environment on Illicit Drug Abuse}

Results on whether availability of drugs could influence the prevalence of illicit drug abuse are recorded as follows;

Table 1: Responses on the Influence of Family Environment on Illicit Drug Abuse

\begin{tabular}{|c|c|c|c|}
\hline & \multicolumn{3}{|c|}{ Responses } \\
\hline Item & $\mathbf{N ~ ( \% )}$ & Disagree & Agree \\
\hline $\begin{array}{c}\text { My parent(s) take drugs in front } \\
\text { of me }\end{array}$ & $340(100)$ & $\mathbf{F ~ ( \% )}$ \\
\hline $\begin{array}{c}\text { My parents don't give me } \\
\text { antidrug use advice }\end{array}$ & $340(100)$ & $50(14.7)$ & $283(83.2)$ \\
\hline $\begin{array}{c}\text { My parents take drugs in front } \\
\text { of my siblings }\end{array}$ & $340(100)$ & $105(30.9)$ & $235(69.1)$ \\
\hline $\begin{array}{c}\text { I can easily access alcohol at } \\
\text { home }\end{array}$ & $340(100)$ & $38(11.2)$ & $302(88.8)$ \\
\hline $\begin{array}{c}\text { The first drug I used was from } \\
\text { my family member }\end{array}$ & $340(100)$ & $40(11.8)$ & $300(88.2)$ \\
\hline Mean & $\mathbf{3 4 0}$ & $\mathbf{7 7 . 8}$ & $\mathbf{2 6 2 . 2}$ \\
\hline Standard Deviation & & $\mathbf{3 7 . 0 9}$ & $\mathbf{3 7 . 0 9}$ \\
\hline
\end{tabular}

When asked whether their parents(s) took drugs in front of them, majority of the students 283(83.2\%) agreed. This was compared to $57(16.8 \%)$ who disagreed with the question implying that indeed parents(s) took drugs in front of them. Thus students end up just abusing drugs without knowing its consequences, and finally become addicted. The study also sought to establish whether parents did not give their children antidrug use advice. Majority of the students 290(85.3\%) agreed compared to 50(14.7\%) who disagreed. This means that students were not given antidrug use advice; they simply modeled drugs users since they were not guided by their parents on how to avoid the menace.

Further, the respondents were asked whether their parents took drugs in front of their siblings. Most of the students 235(69.1\%) agreed compared to 105(30.9\%) who disagreed. This means that students who model their drug using parents are likely to become drug abusers. Students were further asked whether they could easily access alcohol at home, and majority of the respondents 302(88.8\%) agreed compared to $38(11.2 \%)$ who disagreed with the question. This meant that once they easily accessed illicit drugs at home, they may start abusing illicit drugs, which could lead to addiction. The researcher wanted to establish further whether the first drugs the respondents used were from a family member. Majority $300(88.2 \%)$ agreed compared with 40 (11.8\%) who 


\section{International Journal of Science and Research (IJSR) \\ ISSN (Online): 2319-7064 \\ Index Copernicus Value (2013): 6.14 | Impact Factor (2014): 5.611}

disagreed. This implies that those who have relatives who were alcoholics or drug abusers, tended to model the behavior and also if they got the chance of getting the drugs from them, they may start taking drugs and end up becoming addicted to the drugs. Based on the findings as indicated in Table 1, the mean score of the five indicators of family environment influence on illicit drug abuse was 77.8 with a standard deviation of 39.09 in favour of those who disagreed compared to 262.2 with a standard deviation of 39.09 for the respondents who agreed.

\section{Conclusions and Recommendations}

It is concluded that drug abuse within the context of home environment may expose students to drugs thus influencing them to abuse drugs. Moreover students whose peers abused illicit drugs were more likely to abuse drugs than those whose peers were not drug abusers. In addition, if drugs were easily available within home and school surroundings students were more likely to abuse drugs that if drugs were unavailable within the surrounding of the students. Finally, exposure to media with drug content influenced students to abuse drugs. Thus family environment, peer influence, easy availability of drugs and mass media significantly influenced students into drug abuse in secondary schools in Nakuru Municipality. On the basis of the conclusions drawn from the study in respect to the influence of family environment, peer, easy availability of drugs and mass media on drug abuse among secondary school students in Nakuru Municipality, recommendations are made to policy makers, educational planners, implementers and those willing to do research on substance abuse in learning institutions. The school administration needs to closely monitor and counsel students so as to eradicate bad behaviour or influence among students. The schools should also work closely with the community around and other stakeholders to sensitize the students, teachers, non teaching staff and members of community on the dangers of drug abuse in order to curb the vice. In addition, teacher counselors working with drugaffected students should view home environment as an integral part of the curriculum, since early intervention programs may result in long-term positive change only when parents' involvement is emphasized. Policy makers on drug abuse reduction should also link up with local advocacy groups and community-based programmes to come up with a common strategy of reducing drug abuse among youth.

\section{References}

[1] Abdulkarim, A, Mokuolu, O. A, \& Adeniyi, A. (2005). Illicit Drug Use among adolescents in Ilorin, Nigeria. Tropical Doctor 2005; 35: 225-228.

[2] Chebukaka, R. N. (2014). Drug Abuse among Students in Public Secondary Schools in Kenya, The Case of Vihiga County. International Journal of Social Science \& Education (4) 2223-4934.

[3] Croen, L. G., Woesner, M., Hermann, M. \& Reichgott, M. (1997). Substance use and abuse: A longitudinal study of substance use and abuse in a single class of medical students, Academic medicine 72, 376-381.

[4] Elizabeth, B. R., Susan L. D, \& Suman, A. R. (2003). Preventing Illicit Drug Use among Children and Adolescents: A Research-Based Guide for Parents,
Educators, and Community Leaders. New York: National Institute on Drug Abuse.

[5] Jerop, C. S., Chelule, E. \& Barmao, A. C. (2013). An investigation into prevalence and factors contributing to relapse among alcoholism in selected rehabilitation centers in Nairobi County, Kenya. International journal of innovative research and development.

[6] Kingendo, M. (2010). Incidence and Extent of Substance Abuse among Secondary School Students in Nairobi Province, Kenya: Implications for Specialized Intervention. Doctor of Philosophy (Phd), Kenyatta University.

[7] Kingala, Y. M. (2000). Mismanagement of education which results in violence and chaos, a Paper presented at an African convention of principals, St. Stithian College, South Africa.

[8] Kwamanga, D. H. O., Odhiambo, J. A. \& Amukoye, E. I. (2003). Prevalence and risk factors of smoking among secondary school students in Nairobi. EAMJ; 80(4): 207-12.

[9] Mutiso, M. M., Bosco, K. P., Sutter, C. \& Priscillah, W. M. (2012). Factors contributing to drug abuse among the youth in Kenya: A case of Bamburi Location. Elixir Soc. Sci. 46 (2012) 8259-8267.

[10] Ngesu, L. M., Ndiku, J. \& Masese, A. (2008). Drug dependence and abuse in Kenyan secondary Schools: strategies for intervention, Educational Research and Review 3 (10), 304-308.

[11] Oteyo, J. \& Kariuki, M. (2009). Extent to which selected factors contribute to alcohol and cigarette use among public day secondary schools male student: a case of Nakuru municipality, Kenya. Educational Research and Review, 4(6), pp. 327-3.

[12] Otieno, A. O. \& Ofulla, A. V. O. (2009). Drug abuse in Kisumu town western Kenya, Nairobi, African Journal of Food Agriculture Nutrition and Development 6, 3273.

[13] Siringi, S. \& Waihenya, K. (2001). Drug abuse rife as government braces for narcotics war in Kenyan schools.

[14] UNODC (2012). World Drug Report. United Nations Office on Drugs and Crime. United Nations Sales No. E.12.XI.1). Vienna. 